\title{
Ants' Mental Positioning of Amounts on a Number Line
}

\author{
Roger Cammaerts ${ }^{1} \&$ Marie-Claire Cammaerts ${ }^{2}$ \\ ${ }^{1}$ Independent researcher, retired from the Natural and Agricultural Environmental Studies Department (DEMNA) \\ of the Walloon Region, Belgium \\ ${ }^{2}$ Independent researcher, retired from the Biology of Organisms Department, University of Brussels, Belgium \\ Correspondence: Marie-Claire Cammaerts, independent researcher, 27, Square du Castel Fleuri, 1170 Bruxelles, \\ Belgium. Tel: 32-2-673-4969. E-mail: mtricot@ulb.ac.be; mccammaerts@gmail.com
}

Received: November 5, 2019

Accepted: November 22, 2019

Online Published: December 1, 2019

doi:10.5539/ijb.v12n1p30

URL: https://doi.org/10.5539/ijb.v12n1p30

\begin{abstract}
Myrmica sabuleti ants have a mental number line on which numbers (non-symbolic displayed amounts) are ranked, the smaller on the left and the larger on the right. Here we try to know if the difference between two successive numbers is identically estimated all along this line or is less and less well estimated with increasing number magnitude. Ants were trained to distinguish two successive numbers differing by one unit ( 1 vs 2, 2 vs $3, \ldots, 6$ vs 7 ) during 72 hours and tested after 7, 24, 31, 48, 55 and $72 \mathrm{~h}$. The ants responded less well for larger numbers (e.g. their response to $6 v s 7$ was weaker than that to 1 vs 2). The relation between the ants' ability in discriminating two successive numbers according to their relative difference was best described by a non-linear function, a logarithmic function providing a higher fit than a power function. A linear function could only significantly better fit the data when the ratio or the mean of the two numbers was taken into account, particularly in the case of the mean when large fluctuations in the ants' discrimination score appeared in the course of increasing training time. In fact, mean and ratio do not express the relative difference between numbers. Second-order polynomial functions could provide higher fitting, but generally non-significant. The ants' mental positioning of numerosity on their number line appears thus to be compressed along a non-linear scale, most likely according to a logarithmic function.
\end{abstract}

Keywords: Myrmica sabuleti, Number Discrimination, Numerical Cognition, Numerosity, Size Effect

\section{Introduction}

The ability in counting or at least in subitizing sighted (or otherwise perceived) elements exists not only in humans but also in many animal species and has already been rather largely examined at a behavioral as well as at a neurological level. In his book on the number concept and related subjects, Dehaene (2011) details essentially what is nowadays known in humans, above all in children, including the acquisition of this concept, that of the zero notion, and the particularities of these abilities. Concerning the non-human vertebrates, the ability to count or to subitize amounts has been observed in some monkeys, elephants, dogs, birds, frogs and fishes. Rhesus monkeys represent numerosity 1 to 9 at least on an ordinal scale (Brannon \& Terrace, 2000). Number representation in non-trained Old World rhesus monkeys and in New World cotton-top tamarin monkeys equals that of human 10and 12-month old infants (Hauser, MacNeilage, \& Ware, 1996; Hauser, Carey, \& Hauser, 2000; Uller, Carey, \& Hauser, 2001), the limit of the ability of rhesus monkeys in computing additions being set by the ratio difference between two numbers (Flombaum, Junger, \& Hauser, 2005). Concerning elephants, the notion of number could be demonstrated in one individual using relative quantity judgment; its numerosity ability seems to be elementary (Irie, Hiraiwa-Hasegawa, \& Kutsukake, 2019). The ability of dogs to mentally represent quantities, even if obvious, appears to be of low level and lower than that of wolves (Range, Jenikejew, Schröder, \& Virányi, 2014). New Zealand robin birds (Garland \& Low, 2014) and, above all, the grey parrot (Pepperberg, 2006, 2012), show arithmetic competence comparable to that of non-human primates. The spontaneous numerosity ability of amphibians is obvious, also corresponding to the level of that of non-human primates (Uller, Jaeger, Guidry, \& Martin, 2003). Also, some numerosity ability has been reported in fishes, at a level that can be compared to that of some vertebrates (Agrillo, Dadda, Serena, \& Bisazza, 2008; Agrillo, Miletto Petrozzini, \& Bisazza, 2017).

As for the invertebrates, the notion of numbers and the ability in counting have been shown to be detained by spiders, bees, and ants. Spiders are able to count prey and memorize their counts (Rodriguez, Briceno, Briceno-Aguilar, \& Höbel, 2015). Honeybees have been admirably studied as for this topic, three recent works 
needing to be cited (Howard, Avarguès-Weber, Garcia, Greentree, \& Dyer, 2018, 2019a, b). Let us precise that the bees add and subtract numbers when learned to do so under given circumstances. Formica polyctena ants have a counting ability: they can count and even add and subtract the steps they walked while collecting food and transmit this information to congeners (Reznikova \& Ryabko, 2011). The use of odometry while walking exists also in desert ants (Wittlinger, Wehner, \& Wolf, 2006, 2007). Workers of a less evolved ant, Myrmica sabuleti Meinert 1861, have been shown to be able to distinguish different numbers of elements (Cammaerts, 2008). They could add and subtract one visual element or an odor from a number of visual elements or from a mixture of odors when the result of the operation was suggested during training, the tested ants reacting simply to the image or the odor resembling the most to what they perceived during training, and likely when this result is able to be used for efficiently navigating (Cammaerts \& Cammaerts, 2019b, c, d, 2020).

Although a lot of research has been made on the notion of numbers, few works investigated the possession of a mental 'number line' or 'number scale', i.e. the mental association between numbers and space. The existence of such a scale on which individuals instinctively locate the smaller amounts on one side of space (the left side in humans) and the larger ones on the other side has been first demonstrated in humans (Dehaene, Bossini, \& Giraux, 1993). Moreover, in humans, as the numbers increase in size, they are logarithmically compressed into a smaller space before mathematical education transforms it in a linear mapping (Dehaene, 2011). In addition, there exists a numerical distance effect, i.e. the discrimination accuracy between two numbers increases with the numerical distance between them, and a number size effect, i.e. the discrimination accuracy between two numbers decreases as their magnitude increases (Dehaene, Dehaene-Lambertz, \& Cohen, 1998). As for the first point, evidence linking spatial representation of numbers (the number line) with a numerical distance effect was bought from studies of patients with left hemispatial neglect (Umiltà, Priftis, \& Zorzi, 2009). As for the second point, humans' discrimination between amounts decreases with the size of these amounts (Dehaene, 2011). The numerical distance and size effects are commonly seen as the consequence of an analog noisy numerical processing system (the Analog Number System, ANS), working according to Weber's law (i.e. the amount of the just noticeable difference $d$ that needs to be added to or subtracted from a stimulus $I$ is proportional to the stimulus so that $d / I$ is a constant: Nieder \& Miller, 2003). However, the ANS paradigm supports only non-symbolic comparison (e.g. in the form of displayed dots), as symbolic comparison is deemed to be processed by another system, the Discrete Semantic System (DSS) in which the numerical size effect is mainly influenced by the frequency of the symbols (Krajcsi, Lengyel, \& Kojouharova, 2018).

Concerning animals, Rugani, Vallortigara, Priftis and Regolin (2015) experimentally showed that young chicks locate smaller amounts on their left and the larger ones on their right, having thus a spatial representation of numbers, i.e. a number line. Rhesus monkeys also have a native mental number line, as suggested by their discrimination performance along pairs of numbers with increasing size (Hauser et al., 2000). Indeed, Nieder and Miller (2003) showed that when trained to discriminate between numbers 1 to 5 , the neural response of the prefrontal cortex of rhesus monkeys coded for numerosity in a nonlinearly compressed way, i.e. on a logarithmic scale, a power function providing a slightly worse fit. While studying the pigeons' ability in subtracting, Brannon, Wusthoff, Gallistel, and Gibbon (2001) incidentally discovered that these birds have a mental number scale and that their subjective number sense is more likely to be linearly related to the objective numbers (Gallistel, Brannon, Gibbon, \& Wusthoff 2001). A theory explaining left-to-right oriented mental number line based on a different qualitative contribution of each of the two brain hemispheres has been proposed by Vallortigara (2018).

We have shown that the workers of the ant $M$. sabuleti also have a number line, and locate the smaller amounts on the left and the larger ones on the right (Cammaerts \& Cammaerts, 2019e). We also observed that the accuracy of their perception of the difference between amounts decreased when the amounts increased. For example, they appeared to better distinguish 1 element from 2 ones than 4 elements from 5 ones. We presumed that the relation between the ants' accuracy of perception and the sighted amounts of elements could be linear (Cammaerts \& Cammaerts, 2019d, e). However, more data were required for having a more convincing idea of the mathematical function describing this decrease. More data signifies having responses relative to more than four different amounts of elements and having more than one result for each recorded response. We thus here undertook an experimental work which firstly, could allow assessing the accuracy of the ants' response to the difference between six different pairs of non-symbolic elements of increasing size, each pair of two successive amounts differing by one unit. This was done by conditioning ants to a number of sighted elements versus the same number plus one unit and by putting the proportion of correct responses in relation with a variable measuring the magnitude of the amounts, their ratio or a criterion describing the relative difference between the two amounts. Secondly, for each pair of amounts, six assessments were made, regularly spaced out in the course of a 72 hours long training period.

For any animal species, the variable 'accuracy of discrimination between amounts' is accessible and can be quantified, and this variable illustrates the mental characteristic 'kind of amounts arrangement on the number line' 
which is not experimentally accessible and thus cannot be assessed. Therefore, if we could analyze and define the relation between the $M$. sabuleti workers' accuracy of discrimination between amounts and these sighted amounts, we should be able to define what is not accessible: the ants' mental positioning of amounts along their left to right oriented number scale. We here establish whether the relation between the ants' discrimination between amounts of increasing magnitude differing by a fixed distance is linear or non-linear and, in the latter case, if the discrimination obeys to a power, a logarithmic or a more complex function.

\section{Material and Methods}

\subsection{Collection and Maintenance of Ants}

The experiments were conducted on six colonies, labeled A to F, collected in spring and autumn 2018 in two abandoned quarries located at Marchin (Condroz, Belgium) and in the Aise valley (Ardenne, Belgium). The colonies contained about 500 workers, a queen and brood. They were maintained in the laboratory in two to three glass tubes half filled with water, a cotton plug separating the ants from the water. The nest tubes of each colony were set in a tray $(34 \mathrm{~cm} \times 23 \mathrm{~cm} \times 4 \mathrm{~cm})$ which served as foraging area, and in which pieces of Tenebrio molitor larvae (Linnaeus, 1758) were deposited three times per week, and cotton plugged tubes filled with sugar water were permanently set. The ambient temperature was $\mathrm{ca} 20^{\circ} \mathrm{C}$, the humidity $80 \%$, the lighting 330 lux while working on ants, and the electromagnetism $2 \mu \mathrm{Wm}^{2}$. These environmental conditions were optimum for the species.

\subsection{Cues Presented to the Ants}

Colony

A

B

C

D

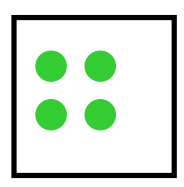
near the food far from the food
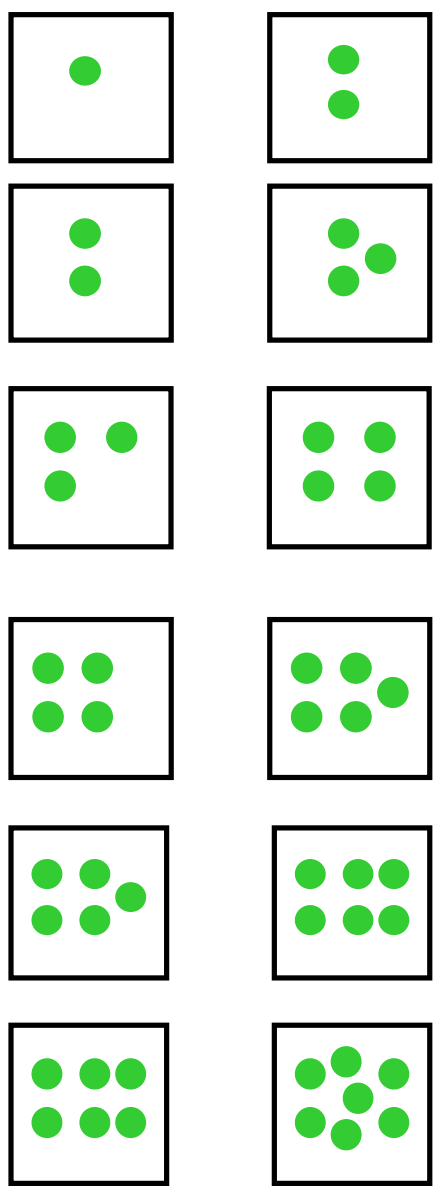

$\mathrm{E}$

F

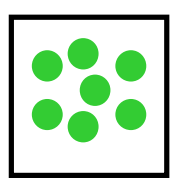

Testing: cues randomly set on the left or the right according to the testing session exactly the same cues as those used for training, but newly built and never used

Figure 1. Green circles tied on a stand, presented to ants for conditioning them to respond to a number of such circles rather than to this number plus one circle

The presentation of these circles to the ants, during their training and their testing, is schematized in Figure 2, and some views of the experiments can be seen in Figure 3. Results and details are given in Table 1 and in the text respectively. 
The elements used were green circles (diameter: $0.4 \mathrm{~cm}$ ), and their numbers were 1 to 7 . The ants of each colony were trained to discriminate between a number of green circles set aside the food (= the correct response) and that number plus one circle set far from the food (= the wrong response). Ants of colony A were trained to, then tested faced with (see below for understanding 'trained' and 'tested') 1 green circle $v s 2$ green circles, ants of colony B were trained to and tested faced with 2 vs 3 circles, those of colony $\mathrm{C}$ were trained to and tested faced with 3 vs 4 circles, those of colony D were trained to and tested faced with $4 v s 5$ circles, those of colony E were trained to and tested faced with 5 vs 6 circles, and ants of colony F were trained to and tested faced with 6 vs 7 circles (Figure 1). The different numbers of green circles were drawn using Power Point ${ }^{\circledR}$, each number inside a $2.5 \mathrm{~cm} \times 2.5 \mathrm{~cm}$ square. The squares with the numbers of circles were printed, cut and tied on the front face of a stand. Each stand was made of strong white paper (Steinbach $\left.{ }^{\circledR}\right)$. The stand had a vertical part $(2.5 \mathrm{~cm} \times 2.5 \mathrm{~cm})$ and a horizontal one [2 $\times(1.25 \mathrm{~cm} \times 0.5 \mathrm{~cm})]$ which, duly folded, allowed their vertical bearing (Figure 2, upper part). For each training session and for each testing session performed on a colony, never used stands bearing the adequate number of green circles were used.

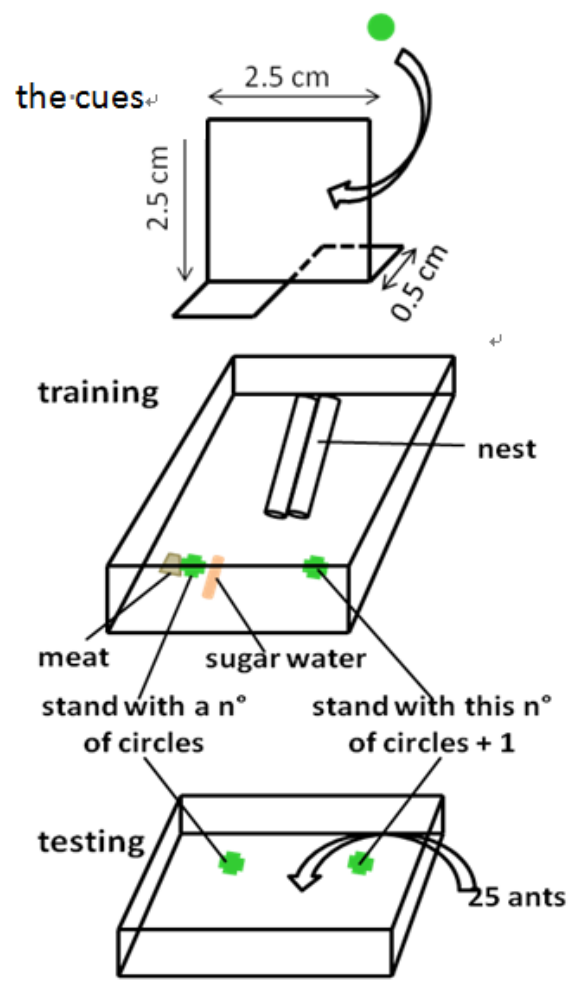

Figure 2. Experimental design used for conditioning the ants of a colony to a number of green circles versus this number plus one circle, and to assess their conditioning score in the course of time

The ants were trained on their foraging area, the number of green circles they must learn being set close to their food, this number plus one circle being set far from the food. The ants were tested over time in a separate tray, in front of the two numbers of green circles randomly set on the left or the right in the tray from one testing session to another. Details are given in the text, numerical results in Table 1, and some photos of the experiments in Figure 3. 


\section{Training}

\section{Testing}

Experiment I, 1 vs 2, colony A
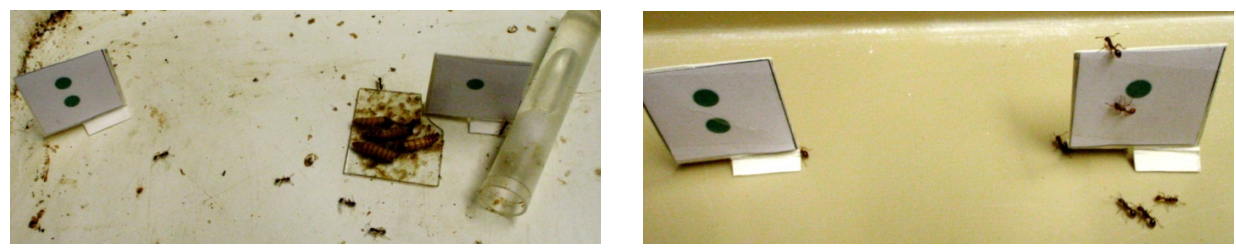

Experiment II, 2 vs 3, colony B
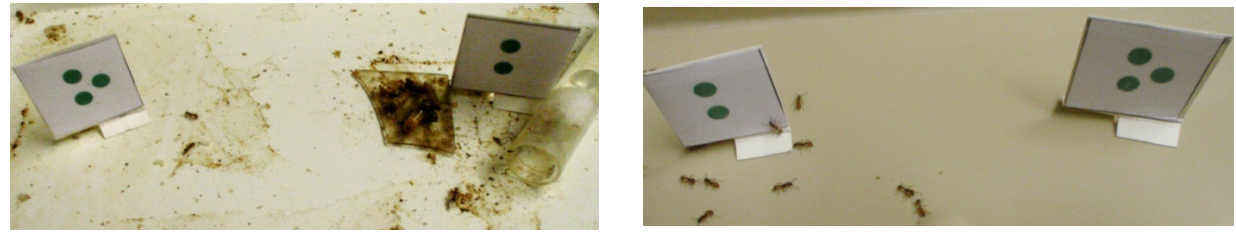

Experiment III, 3 vs 4, colony C
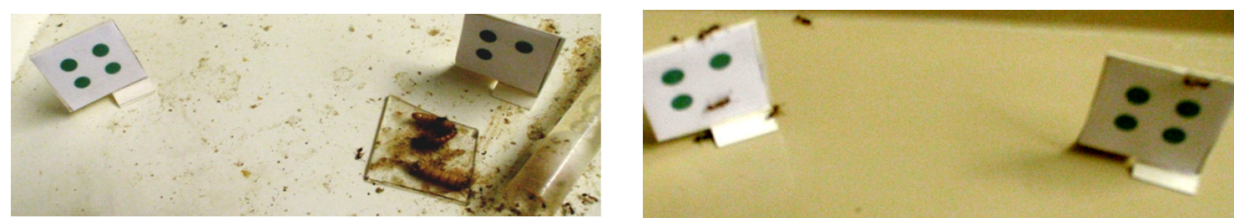

Experiment IV, 4 vs 5, colony D
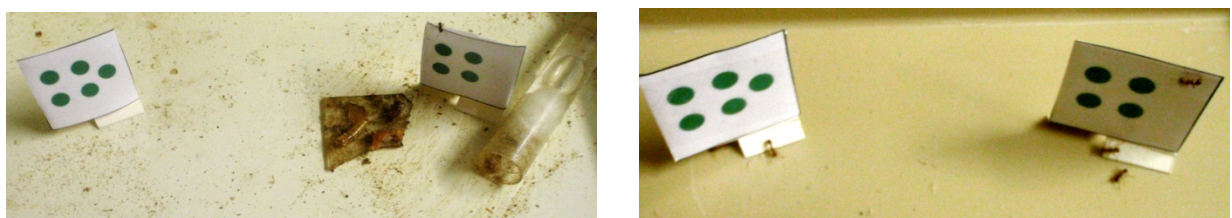

Experiment V, 5 vs 6, colony E
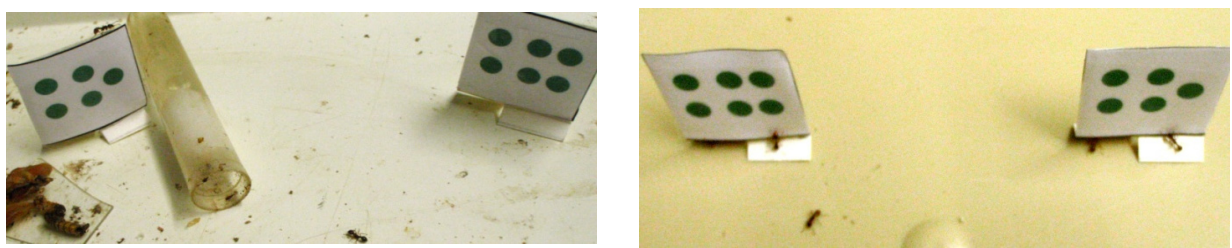

Experiment VI, 6 vs 7, colony F
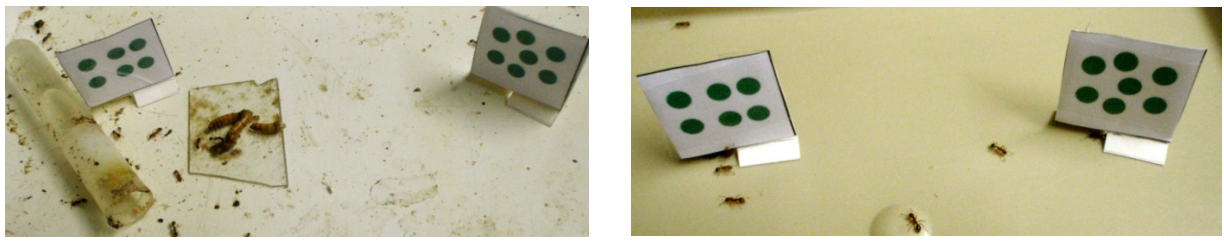

Figure 3. Some photos of the experiments made to approach the number arrangement on the ants' number line

The ants were trained to a number of green circles set close to the food and in the presence of this number plus one circle set far from the food. They were tested in a separate tray faced with these two numbers of circles. The ants essentially reacted to the number of circles set aside the food during training, and did so less and less well for increasing numbers of circles (Table 1). Graphical (Figure 4) as well as statistical analysis (Table 2) showed that this decrease varied non-linearly with the mean, the ratio or the relative difference between the two sighted numbers. 


\subsection{Experimental Design}

This design is schematically presented in Figure 2.

The ants were trained during three days on their foraging area, the smaller number of circles being set aside the food ( $=$ the reward) and the larger number ( $=$ the smaller number +1 circle) being set far from the food. The ants were tested after $7 \mathrm{~h}, 24 \mathrm{~h}, 31 \mathrm{~h}, 48 \mathrm{~h}, 55 \mathrm{~h}$ and $72 \mathrm{~h}$ of training (times chosen for experimental and personal convenience purpose) in a separate tray $(30 \mathrm{~cm} \times 15 \mathrm{~cm} \times 4 \mathrm{~cm})$, different for each colony. The borders of this tray were slightly covered with talc to prevent ants' escaping, and the two stands bearing the two numbers of green circles were set inside it, being randomly located at the left or at the right in the tray from one testing session to another.

\subsection{Experimental Protocol}

Training of colony A started at day 1 , at $\mathrm{t}=0 \mathrm{~h}$, and testing of these ants occurred $7 \mathrm{~h}, 24 \mathrm{~h}, 31 \mathrm{~h}, 48 \mathrm{~h}, 55 \mathrm{~h}$ and $72 \mathrm{~h}$ later. At that time, training of ants of colony A ended, and training of ants of colony B began. These ants were tested $7 \mathrm{~h}, 24 \mathrm{~h}, 31 \mathrm{~h}, 48 \mathrm{~h}, 55 \mathrm{~h}$ and $72 \mathrm{~h}$ later. In the same way, then, training of ants of colony B ended and that of ants of colony $\mathrm{C}$ began. They were tested over time as the previous tested ants, and after $72 \mathrm{~h}$ their training ended and that of ants of colony $\mathrm{D}$ began. The same events occurred for colony $\mathrm{D}$, and after that, again for colonies $\mathrm{E}, \mathrm{F}$, and $\mathrm{G}$ consecutively. The entire experimental work performed on the six colonies lasted thus 18 days. During training, the ants present all around the two presented cues were counted twice per day, and the means of these counts was established (and is given in the text only).

For testing, 25 ants of the experimented colony were transferred into the tray devoted to test, and the ants present at a distance of $0-2 \mathrm{~cm}$ from each stand were counted 20 times over 10 minutes. This allowed calculating the proportion of correct responses given by the ants after $7 \mathrm{~h}, 24 \mathrm{~h}, 31 \mathrm{~h}, 48 \mathrm{~h}, 55 \mathrm{~h}$ and $72 \mathrm{~h}$ of training. After each test, the ants were replaced in their foraging area.

\subsection{Statistical Analysis}

The ants' discrimination accuracy between two successive numbers of increasing size (e.g. $\mathrm{n} 1$ and $\mathrm{n} 2$, ranging from 1 to 7) differing by 1 unit was assessed by the proportion of correct responses recorded during each testing session of each experiment (Table 1, columns 2-7). For each pair of numbers, the amount of fluctuation of the ants' score along time was established by its coefficient of variation (Table 1, column 9). For each experiment, the mean of the correct responses obtained in the course of the six testing sessions was calculated (Table 1, column 8), using not the six successively obtained proportions reported in Table 1, but the numbers of ants counted at each testing session, which numbers are given in the text.

The accuracy of the response was put in relation to the magnitude of the amounts by using their mean (e.g. $(\mathrm{n} 1+\mathrm{n} 2) / 2=1.5,2.5,3.5$, etc.), their ratio (e.g. $\mathrm{n} 1 / \mathrm{n} 2=1 / 2,2 / 3,3 / 4$, etc.) or their relative difference, the latter expressed either by their difference divided by their mean (e.g. $(\mathrm{n} 2-\mathrm{n} 1) /(\mathrm{n} 1+\mathrm{n} 2) / 2=1 / 1.5,1 / 2.5,1 / 3.5$, etc.) or divided by the smaller of the two numbers (e.g. $(n 2-n 1) / n 1=1 / 1,1 / 2,1 / 3$, etc., the smaller number being the one to which the ants were conditioned) or divided by the larger of the two numbers (e.g. (n2-n1)/n2 =1/2,1/3, 1/4, etc., what is equivalent to the complement of their ratio). The sum of the two numbers was not taken into account because it has been shown that the ants failed to add numbers of elements when not sighted all together (Cammaerts \& Cammaerts, 2019c).

Using Statistica v10 software we examined the appropriateness of mathematical functions which could describe the relation between the ants' responses and the numbers of circles they should discriminate. The $\mathrm{R}^{2}$ goodness-of-fit determination index (least squares, Levenberg-Marquardt method) was used to compare the adequacy of the theoretical curves with the observed data (Table 2). Linear $\left(y=a+b^{*} x\right)$, logarithmic $(y=a+$ $\left.b^{*} \log \mathrm{x}\right)$ and power $\left(\mathrm{y}=\mathrm{a}+\mathrm{b}^{*} \mathrm{x}^{\mathrm{power}}\right)$ functions were tried, the latter first-order functions with exponents 0.33 and 0.50 . These radical functions are those of the cubic and square roots of the predictor $\mathrm{x}$ which in humans correspond to subjective brightness magnitude related to the stimulus magnitude, the exponent 0.33 for a large-sized target and 0.50 for a point-sized target (Stevens, 1961). These exponents were also used by Nieder \& Miller (2003) and by Verguts \& Fias (2004). Power functions with higher and lower exponents were not worth useful because they approached power functions bearing exponent 1 (i.e. a linear function) or 0 (i.e. a logarithmic function). Power functions with exponent higher than 1 were not considered because they produced outward directed curves with respect to the curvature of the observed data. The level of significance of the coefficient $b$ of these functions was set at $\alpha=0.05$, what determined if the curve could significantly represent the observed data.

As a comparison, because they provided a higher fit to the observed data, second-order fractional polynomial functions of the kind $y=a+b^{*} x+c^{*} x^{\text {power }}$ were also tried, their second term bearing exponent $0.10,0.33,0.50$ or 2 (in the last case it is a quadratic polynomial) or being the logarithm of $\mathrm{x}$. No further development of a polynomial 
was tried because the aim was only to show the fitting improvement by using second-order polynomials instead of first-order functions. Rejection of the significance of the coefficient $\mathrm{c}$ of the second term of the polynomial was considered at two $\alpha$ levels, 0.05 and 0.10 (since $P$ often ranged from 0.05 to 0.07 ). When this second term did not significantly improve the description of the dependence of $\mathrm{y}$ on $\mathrm{x}$, a linear regression remained sufficient for describing this dependence (Zar, 1999). The interest of second-order polynomial functions is that they express a higher proportion of the total variation in $\mathrm{y}$ than the other functions used in this paper, but they are biologically more difficult to interpret since they depend on two variables ( $\mathrm{x}$ and a transformation of $\mathrm{x}$ ).

\section{Results}

Numerical results concerning discrimination scores are given in Table 1, photos of the experiments are shown in Figure 3.

Table 1. Proportions of correct responses presented by ants in the course of their conditioning to a number of green circles set close to their food versus this number plus 1 circle set far from the food

\begin{tabular}{|c|c|c|c|c|c|c|c|c|}
\hline \multirow{2}{*}{$\begin{array}{l}\text { Discriminated } \\
\text { numbers, } \\
\text { colony used }\end{array}$} & \multicolumn{6}{|c|}{ Proportion (\%) of correct responses presented after } & \multirow{2}{*}{$\begin{array}{l}\text { Average } \\
\text { score }\end{array}$} & \multirow{2}{*}{$\begin{array}{l}\text { Coefficient of } \\
\text { variation (\%) }\end{array}$} \\
\hline & $7 \mathrm{~h}$ & $24 \mathrm{~h}$ & $31 \mathrm{~h}$ & $48 \mathrm{~h}$ & $55 \mathrm{~h}$ & $72 \mathrm{~h}$ & & \\
\hline 1 vs $2, \quad A$ & 78.7 & 80.3 & 86.4 & 88.2 & 84.7 & 84.2 & 83.1 & 43.2 \\
\hline $2 v s 3, \quad$ B & 73.7 & 74.7 & 78.3 & 82.3 & 85.9 & 78.1 & 79.1 & 58.5 \\
\hline 3 vs 4, C & 67.2 & 71.2 & 76.1 & 84.6 & 75.5 & 82.5 & 76.0 & 86.4 \\
\hline 4 vs 5, D & 63.8 & 69.2 & 70.7 & 77.7 & 81.1 & 71.9 & 73.0 & 85.4 \\
\hline $5 v s 6, \quad \mathrm{E}$ & 61.1 & 64.1 & 67.5 & 73.0 & 69.0 & 74.8 & 68.5 & 76.1 \\
\hline 6 vs $7, \quad F$ & 60.6 & 63.4 & 66.7 & 72.4 & 68.5 & 69.4 & 66.9 & 63.8 \\
\hline
\end{tabular}

The ants' discrimination accuracy between two successive numbers decreased with increasing number magnitude. The coefficient of variation of the ants' score over their training showed that the highest fluctuations occurred when they were trained to numbers 3 vs 4,4 vs 5 and 5 vs 6 (colonies C, D, E respectively).

\subsection{Discrimination between 1 and 2 Elements}

During their training, the ants of colony A were rather numerous all around the two presented cues, being meanly 7.6 at any time on that area. Tested after $7 \mathrm{~h}$, they already went essentially to the stand bearing 1 green circle: 151 ants were counted in front on that stand, and 41 ants in front of that bearing 2 green circles. The ants' proportion of correct responses equaled thus $78.7 \%$. After $24 \mathrm{~h}$ of training, 147 tested ants were counted in front of the stand bearing 1 green circle while 36 ones were counted in front of the stand with 2 green circles, the ants having thus reached a conditioning score of $80.3 \%$. After having been trained for $31 \mathrm{~h}$, the tested ants still more approached the stand with 1 circle (they were 70 in doing so) than that with 2 circles (11 ants were counted there), the ants' proportion of correct responses equaling thus $86.4 \%$. After $48 \mathrm{~h}$ of training, the tested ants promptly reacted to the stand with 1 green circle (112 ants were counted there), and only few went to the other stand (15 ants), the proportion of correct responses equaling thus $88.2 \%$. After a total of 55 training hours, 161 tested ants were counted in front of 1 green circle, and 29 ants in front of 2 green circles, the ants' conditioning score equaling thus $84.7 \%$. After $72 \mathrm{~h}$ of training, the tested ants responded to 1 green circle with a score of $84.2 \%$ (i.e. 112 ants seen near 1 circle and 21 ants seen near 2 circles). The maximum conditioning score of about $90 \%$ was thus reached in about two days. The average of the successively obtained correct responses equaled $83.1 \%$.

\subsection{Discrimination between 2 and 3 Elements}

During their training, the ants of colony B were rather numerous all around the two presented stand for seeing and memorizing the sighted numbers of green circles. They were in fact meanly 9.8 at any time in doing so. Tested after $7 \mathrm{~h}$ of training, the ants already went preferentially to the stand bearing 2 green circles: 42 ants were counted there, and 15 in front of 3 circles, the ants' conditioning score equaling thus $73.7 \%$. After $24 \mathrm{~h}$ of training, 59 ants were counted in front of 2 circles and 20 ants in front of 3 circles, their conditioning score being thus of $74.7 \%$. After having been trained during $31 \mathrm{~h}$, the ants still somewhat more reacted to 2 circles: 47 ants were seen near 2 circles and 13 ones near 3 circles, the ants' conditioning reaching thus the score of $78.3 \%$. After two training days, 65 ants were counted near 2 circles and 14 ones near 3 circles, the ants presenting a conditioning score of $82.3 \%$. After having been trained during 55h, the ants reacted essentially to 2 circles: 67 ones were counted in front of that cue while 11 ants were counted in front of 3 circles, the ants' proportion of correct responses reaching then a maximum of $85.9 \%$. After a total of three training days, 57 tested ants were counted in front of 2 circles, and 16 ones in front of 3 circles, the ants' conditioning score equaling $78.1 \%$. The average of the ants' correct responses equaled $79.1 \%$. 


\subsection{Discrimination between 3 and 4 Elements}

While being trained, the ants of colony $\mathrm{C}$ were rather numerous in moving or staying in the vicinity of the two presented cues. They were meanly 9 in doing so at any time. Tested after 7 training hours, 78 ants were counted in front of 3 circles and 38 ones were counted in front of 4 circles, the ants' proportion of correct responses equaling thus $67.2 \%$. After one training day, the ants became more inclined to approach the stand bearing 3 circles, 74 ants having been counted near that stand and 30 ones near the stand with 4 circles. The ants' conditioning score equaled then $71.2 \%$. After having been trained during $31 \mathrm{~h}$, the ants went more to the stand with 3 circles than to that with 4 circles: 67 ants were counted in front of 3 circles and 21 ants in front of 4 circles, the ants' proportion of correct responses equaling $76.1 \%$. After two training days, 88 ants were counted in front of 3 circles and 16 ones in front of 4 circles, the ants having then reached their maximum conditioning score of $84.6 \%$. After $55 \mathrm{~h}$ of training, 71 ants were counted in front of 3 circles and 23 ones in front of 4 circles, the ants' proportion of correct responses equaling thus $75.5 \%$. After three training days, the ants also responded essentially to 3 circles: 80 ants were counted in front of that number of circles and 17 ones in front of 4 circles, the ants' conditioning score equaling thus $82.5 \%$. The average of the ants' correct responses over the 72 experimental hours equaled $76.0 \%$.

\subsection{Discrimination between 4 and 5 Elements}

During training, several ants of colony D were seen at any time all around the two presented cues: meanly 9.4 ants have been counted on this area. After 7 training hours, the tested ants slightly more reacted to 4 circles than to 5 circles: 37 ants were counted near 4 circles and 21 ones near 5 circles, the proportion of ants' correct responses equaling thus $63.8 \%$. After one training day, the ants were more inclined to move preferentially to the stand bearing 4 green circles: 65 ants were counted there and 29 ones in front of the stand with 5 circles, the ants' proportion of correct responses equaling thus $69.2 \%$. After 31 training hours, 87 ants were seen near the stand with 4 circles, and 36 ants near the stand with 5 circles, the ants' conditioning score equaling $70.7 \%$. After two training days, 108 ants were counted in front of 4 circles and 31 ones in front of 5 circles, the ants' conditioning score equaling thus $77.7 \%$. After 55 training hours, 60 ants were counted in front of the 4 circles and 14 ones in front of the 5 circles, the proportion of ants' correct responses equaling its maximum of $81.1 \%$. After three training days, the number of ants in front of 4 circles equaled 69 and that of ants in front of 5 circles equaled 27, the ants' conditioning score being thus of $71.9 \%$. The average of the ants' correct responses obtained in the course of the six assessments made over time equaled $73.0 \%$.

\subsection{Discrimination between 5 and 6 Elements}

During their training, the ants of colony E were rather numerous at any time all around the two presented cues. Meanly 9 ants were counted on this area. Tested after 7 training hours, the ants were slightly inclined to approach the stand bearing 5 circles: 44 ants were counted in front of that stand and 28 ones in front of the stand with 6 circles, the ants' proportion of correct responses being thus of $61.1 \%$. After one training day, the ants went somewhat more frankly to the stand bearing 5 circles: 50 ants were counted in front of that stand and 28 ants in front of the stand with 6 circles, the ant proportion of correct responses equaling thus $64.1 \%$. After 31 training hours, 56 ants were counted near the stand with 5 circles, and 27 ones in front of that with 6 circles, the ants' proportion of correct responses equaling then $67.5 \%$. After two training days, 46 ants were counted in front of 5 circles and 17 ones in front of 6 circles, the ants having thus reached their maximum conditioning score of $73.0 \%$. After 55 training hours, 80 ants were counted near 5 circles and 36 ants near 6 circles, the ants' proportion of correct responses equaling thus $69.0 \%$. After three training days, 77 ants were seen near 5 circles and 26 ants near 6 circles, the ants' proportion of correct responses equaling $74.8 \%$. The average of the correct responses obtained over the three experimental days equaled $68.5 \%$.

\subsection{Discrimination between 6 and 7 Elements}

During their training to 6 circles set near the food and 7 circles set far from the food, the ants of colony F were numerous in foraging all around these two cues. They were indeed meanly 12.8 in doing so at any time. Tested after 7 training hours, the ants slightly moved more to the stand with 6 circles than to that with 7 circles: the ants counted near 6 circles were 57, and those counted near 7 circles were 37 . The ants' proportion of correct responses equaled thus $60.6 \%$. After one training day, the ants somewhat better responded to 6 circles: 45 ants were counted in front of 6 circles and 26 ones in front of 7 circles, the ants' proportion of correct responses equaling thus $63.4 \%$. After 31 training hours, 58 ants were counted near 6 circles and 29 ants near 7 circles, the ants' conditioning score reaching $66.7 \%$. After two training days, 63 ants were counted in front of 6 circles and 24 ones in front of 7 circles, the ants' conditioning score reaching its maximum of $72.4 \%$. After 55 training hours, 61 ants were seen near 6 circles and 28 ants near 7 circles, the ants' proportion of correct responses equaling $68.5 \%$. After three training 
days, 59 ants were counted near 6 circles and 26 ones near 7 circles, the ants' conditioning score equaling then $69.4 \%$. The average of the correct responses obtained in the course of the 72 conditioning hours equaled $66.9 \%$.

\subsection{Relation between Discrimination Accuracy and Increasing Magnitude of Successive Numbers (Table 2 and} Figure 4)

The relation between the ants' conditioning scores (i.e. their accuracy of discrimination) and the pairs of numbers of sighted circles depended on the predictors (independent variables) used to describe the difference between the two numbers and changed in the course of the training period. The $\mathrm{R}^{2}$ determination index was used to assess the goodness-of-fit of this relation (Table 2). We here begin by comparing the fitting of linear, power and logarithmic functions with the observed data and end by the fitting of polynomial functions.

When the relation between the ants' score and the size of the successive pairs of numbers was approached by the mean of the latter, a logarithmic or some power function appeared to fit the best with the observed data up to 31 training hours. For higher training times as well as for the average score of the six assessments made in the course of the 72 training hours, a linear function described the best the relation, obviously due to important switchback fluctuations of the scores along training time (see Table 1 and Figure 4).

When the relation between the ants' scores and the ratio of the sighted numbers was taken into account, a linear function appeared to provide the best significant fit with the observed data, except for 55 and 72 training hours, due to the high level of the score fluctuations then occurring. These fluctuations also accounted for a low linear fit when the average score was taken into account.

Mean and ratio of the successive numbers express either (for the mean) the magnitude of the numbers but not their difference, or (for the ratio) a proportion between two numbers but not their magnitude. Therefore, they appeared not to be good predictors for explaining the relation between discrimination ability and sighted numbers.

When the relation between the ants' scores and a relative difference between the successive amounts was taken into account, a logarithmic function provided a better fit to this relation than a linear or a power function, whatever how this relative difference was calculated, e.g. by dividing the difference between two successive amounts by their mean, by the smaller (i.e. the number to which the ants were conditioned) or by the larger of the two amounts or, equivalently to the last-mentioned case, by using the proportion of the larger amount that exceeded the smaller one.

A second-order polynomial function generally provided a somewhat higher fit to the observed data, but its second term was generally non-significant, so that a linear function was then sufficient to describe the relation. Fractional polynomials with exponent 0.10 or 0.50 or with $\mathrm{c}^{*} \log \mathrm{x}$ for second term provided nearly similar fitting as with exponent 0.33 and were therefore not displayed in Table 2.

To summarize, the ants reacted to the gap between two sighted amounts (non-symbolic numbers) differing by a same distance (one unit) proportionally to the size of these amounts, the relation being non-linear when a relative difference between the amounts was taken into account. When second-order polynomial functions were set aside, the ants' discrimination ability between two successive amounts appeared then to obey to a logarithmic function. A relative difference between amounts is most likely the kind of difference the ants perceived when discriminating numbers; The ants' corresponding score reflects their mental compressed positioning of numbers on an oriented number scale. This is valid as soon as for the first seven sighted elements.

Important score fluctuations occurred in three of the societies (tested for numbers 3 vs 4,4 vs 5 and 5 vs 6 ) after 31 hours training. It has been already shown that any conditioning is firstly rapidly acquired, reaches a first level, then slowly goes on, somewhat varying over time (e.g. in Cammaerts, Rachidi, \& Cammaerts, 2011). If we take only account of the testing times up to 31 hours, the relation between discrimination accuracy and the mean of successive numbers was best described by a non-linear function. As for the relation between ratio of successive numbers and ant's score, it appeared to correspond the best to a linear function. Such a linear relation may appear because the ratio expressed essentially the difference in size between the two numbers, and only partially their magnitude.

It should be noted that the expected curves for the here used functions were closely situated, intersect and moreover were based on only six points, so that their difference could not be underlined by using either the Royston \& Altman's (1994) deviance test based on the log-likelihood goodness-of-fit test, the Wilcoxon sign-ranked test or the Friedman ANOVA test.

The relation between the ants' scores and the ratio between two successive numbers did not obey to an exponential decrease, since using the logarithm of the ants' scores leaded to significant curvilinear relations. 
Contrary to logarithmic and power functions, second order polynomial functions provided non-monotonic curves with a maximum (apex) around the discrimination score corresponding to 1 vs 2 . Therefore, they should show a lesser discrimination score for the smallest possible pair, $0 v s$, a pair that was not tested in the present work, although it was shown (Pinhas \& Tzelgov, 2012) that zero can be perceived as the smallest entity on the mental number line. A 0 vs 1 pair was tested in a previous work (Cammaerts \& Cammaerts, 2019a), by assessing on two colonies the ants' discrimination between a stand bearing a black circle and an empty stand after 24, 48 and 72 training hours. As in the present work, the score increased in the course of training time. The mean scores were $67.6 \%$ and $75.3 \%$, and the mean of them equaled $71.4 \%$, less than for the $1 v s 2$ discrimination obtained in the present work. Placed in the series of the average scores of the present discriminations between two successive numbers, a 0 vs 1 pair could perfectly be inserted in the curve of a fractional polynomial function, the $\mathrm{R}^{2}$ value of which and the probability of the parameter associated with the power of its last term being in the range of those of the curves describing the here studied 1 vs 2 to 6 vs 7 discriminations (results not in a Table or a Figure).

\section{Discussion and Conclusion}

Having previously found that the accuracy of the response of Myrmica sabuleti ants to numbers (quantities) decreases with increasing number magnitude (Cammaerts \& Cammaerts, 2019d), that these ants represent the numbers on a left to right oriented scale and having presumed that this number arrangement could be linear (Cammaerts \& Cammaerts, 2019e), we here tempted to define the kind of arrangement they have on their number line by using their ability to discriminate between two successive numbers ranging from 1 to 7 .

By training ants to distinguish two successive numbers (non-symbolic amounts) and testing them faced with a series of pairs of these numbers which absolute distance was kept constant (one unit), we observed that the accuracy of their response after 7 training hours, as well as their average response over six tests performed along 72 training hours depended on the magnitude of the numbers. The ants' discrimination accuracy between numbers decreased according to the mean, the ratio or the relative difference of these numbers (i.e. their difference divided by their mean or by one of the two numbers of the pair). A linear relation between discrimination score and amounts appeared for the ratio, thus when the magnitude of the numbers was only partially expressed, and for the mean size of the pairs when large score fluctuations appeared in the course of training time. When each pair was expressed by the relative difference between its two numbers, the relation between number discrimination accuracy and number size obeyed the best to a non-linear function, the ants' response corresponding better to a logarithmic function than to a power function. Polynomial second-order functions always provided a higher fit than a linear function, but generally non-significant, also suggesting that the ants' mental positioning of numerosity on a number line appears compressed along a non-linear scale.

As did other researchers, we did not include the zero in our series of number comparisons. However, probing the reaction time of participants faced with size comparisons that do not require a task intentionally performed, and are thus automatically processed, Pinhas and Tzelgov (2012) showed that zero is the smallest entity on the human number line which extends to the right. This was already experimentally supported from parity judgments and numerical comparisons by Fischer and Rottmann (2005). Besides that, it may be related that Merritt, Rugani \& Brannon (2009) showed that rhesus monkeys treat the non-symbolic number zero (an empty set) as smaller in numerical magnitude than nonempty sets and place it on a numerical continuum.

Polynomial functions describing the ants' discrimination accuracy between successive numbers were in most cases non-monotonic, decreasing in the direction of the $0 v \mathrm{~s} 1$ pair instead of continuously increasing from the largest to the smallest sized pair. In the course of a previous study we made on the ants' notion of zero (Cammaerts \& Cammaerts, 2019a), we indeed found a discrimination score between 1 and zero of meanly about $71 \%$, thus a value lower than the score here observed for the ants' discrimination between 1 and 2 . Thus, a polynomial function may better describe the ants' positioning of amounts on the number line than a logarithmic, monotonic function. The lower score observed for the 0 vs 1 pair of numbers may be due to the fact that not all the tested ants had the notion of zero, such a notion having perhaps to be acquired in the course of their life.

Cantlon and Brannon (2006) showed that the accuracy discrimination between numbers in rhesus monkeys and in humans is non-linearly related to the ratio between the magnitudes of a wide range of numerical pairs with various intrapair distances. The accuracy decreased as the ratio increased, a process controlled by Weber's law. In the present work we showed that the ants' discrimination accuracy depended on the ratio of numbers differing by a same distance, a size effect also predicted by Weber's law. In our work on ants the number magnitude was not put at the limit where discrimination should become null (i.e. a conditioning score of 50\%) and we did not tempt to test if the accuracy of response at a given ratio was constant across pairs of numbers differing by their intrapair distance. We also did not try to assess the ants' discrimination between displayed amounts of equal density, surface area and perimeter or between numbers represented by different features (shapes, colors, 
locations) in order to work at a level of a more abstract numerosity.

Table 2. Functions describing the relation of the ants' discrimination accuracy between two successive numbers of increasing size (from 1 to 7 ), to these numbers' magnitude, ratio or relative difference

\begin{tabular}{|c|c|c|c|c|c|c|}
\hline Training & Linear & Power, 0.50 & Power, 0.33 & Log & Polyn., 0.33 & Polyn., 2 \\
\hline \multicolumn{7}{|c|}{ Using the mean of two successive numbers: $(n 1+n 2) / 2$} \\
\hline 7 hours & 0.9308 & 0.9683 & 0.9761 & 0.9829 & 0.9857 & 0.9943 \\
\hline 24 hours & 0.9643 & 0.9833 & 0.9850 & 0.9811 & 0.9851 (NS) & 0.9840 (NS) \\
\hline 31 hours & 0.9403 & 0.9724 & 0.9788 & 0.9840 & $0.9840(\mathrm{~ns})$ & 0.9835 (ns) \\
\hline 48 hours & 0.9006 & 0.8881 & 0.8793 & 0.8560 & 0.9008 (NS) & 0.9007 (NS) \\
\hline 55 hours & 0.7778 & 0.7503 & 0.7366 & 0.7042 & 0.7896 (NS) & 0.7868 (NS) \\
\hline 72 hours & 0.7439 & 0.7352 & 0.7289 & 0.7119 & $0.7436(\mathrm{NS})$ & $0.7442(\mathrm{NS})$ \\
\hline average & 0.9915 & 0.9909 & 0.9855 & 0.9675 & 0.9938 (NS) & 0.9941 (NS) \\
\hline \multicolumn{7}{|c|}{ Using the ratio between two successive numbers: $\mathrm{n} 1 / \mathrm{n} 2$} \\
\hline 7 hours & 0.9617 & 0.9478 & 0.9425 & 0.9313 & $0.9913(\mathrm{~ns})$ & 0.9897 (ns) \\
\hline 24 hours & 0.9413 & 0.9259 & 0.9202 & 0.9084 & $0.9793(\mathrm{~ns})$ & $0.9810(\mathrm{~ns})$ \\
\hline 31 hours & 0.9625 & 0.9511 & 0.9467 & 0.9374 & $0.9812(\mathrm{NS})$ & $0.9822(\mathrm{NS})$ \\
\hline 48 hours & 0.7828 & 0.7622 & 0.7550 & 0.7406 & 0.8693 (NS) & 0.8773 (NS) \\
\hline 55 hours & 0.6164 (ns) & $0.5910(\mathrm{~ns})$ & $0.5822(\mathrm{~ns})$ & $0.5648(\mathrm{~ns})$ & 0.7936 (NS) & 0.7942 (NS) \\
\hline 72 hours & 0.6569 (ns) & $0.6419(\mathrm{~ns})$ & $0.6365(\mathrm{~ns})$ & 0.6259 (ns) & 0.7107 (NS) & 0.7176 (NS) \\
\hline average & 0.8995 & 0.8776 & 0.8697 & 0.8539 & 0.9851 & 0.9881 \\
\hline \multicolumn{7}{|c|}{ Using the difference between two successive numbers divided by their mean: $(\mathrm{n} 2-\mathrm{n} 1) /(\mathrm{n} 1+\mathrm{n} 2) / 2$} \\
\hline 7 hours & 0.9383 & 0.9718 & 0.9784 & 0.9829 & 0.9849 (ns) & 0.9924 \\
\hline 24 hours & 0.9154 & 0.9570 & 0.9675 & 0.9811 & 0.9839 & $0.9780(\mathrm{~ns})$ \\
\hline 31 hours & 0.9429 & 0.9831 & 0.9793 & 0.9840 & $0.9838(\mathrm{~ns})$ & 0.9803 (ns) \\
\hline 48 hours & 0.7488 & 0.8073 & 0.8254 & 0.8560 & 0.8893 (NS) & 0.8645 (NS) \\
\hline 55 hours & $0.5753(\mathrm{~ns})$ & $0.6434(\mathrm{~ns})$ & 0.6653 & 0.7042 & 0.7958 (NS) & 0.7929 (NS) \\
\hline 72 hours & $0.6319(\mathrm{~ns})$ & 0.6758 & 0.6892 & 0.7119 & 0.7295 (NS) & 0.7065 (NS) \\
\hline average & 0.8633 & 0.9228 & 0.9401 & 0.9675 & 0.9923 & 0.9832 \\
\hline \multicolumn{7}{|c|}{ Using the difference between two successive numbers divided by the smaller number: $(\mathrm{n} 2-\mathrm{n} 1) / \mathrm{n} 1$} \\
\hline 7 hours & 0.8924 & 0.9496 & 0.9637 & 0.9798 & 0.9867 & 0.9959 \\
\hline 24 hours & 0.8686 & 0.9314 & 0.9488 & 0.9738 & 0.9826 & 0.9719 \\
\hline 31 hours & 0.9047 & 0.9552 & 0.9678 & 0.9823 & 0.9832 & $0.9756(\mathrm{~ns})$ \\
\hline 48 hours & 0.6955 & 0.7713 & 0.7959 & 0.8386 & 0.8805 (NS) & 0.8428 (NS) \\
\hline 55 hours & 0.5119 (NS) & $0.5978(\mathrm{~ns})$ & $0.6269(\mathrm{~ns})$ & 0.6796 & 0.7968 (NS) & 0.7891 (NS) \\
\hline 72 hours & 0.5924 (ns) & $0.6496(\mathrm{~ns})$ & 0.6681 & 0.6997 & 0.7216 (NS) & 0.6881 (NS) \\
\hline average & 0.8033 & 0.8848 & 0.9100 & 0.9513 & 0.9899 & 0.9734 \\
\hline \multicolumn{7}{|c|}{ Using the difference between two successive numbers divided by the larger number: $(\mathrm{n} 2-\mathrm{n} 1) / \mathrm{n} 2=1-(\mathrm{n} 1 / \mathrm{n} 2)$} \\
\hline 7 hours & 0.9617 & 0.9807 & 0.9833 & 0.9822 & 0.9844 (NS) & $0.9897(\mathrm{~ns})$ \\
\hline 24 hours & 0.9413 & 0.9697 & 0.9763 & 0.9839 & 0.9845 (NS) & $0.9810(\mathrm{~ns})$ \\
\hline 31 hours & 0.9625 & 0.9804 & 0.9831 & 0.9831 & 0.9839 (NS) & 0.9823 (NS) \\
\hline 48 hours & 0.7828 & 0.8292 & 0.8431 & 0.8665 & 0.8941 (NS) & 0.8774 (NS) \\
\hline 55 hours & $0.6163(\mathrm{~ns})$ & 0.6714 & 0.6887 & 0.7191 & 0.7949 (NS) & 0.7943 (NS) \\
\hline 72 hours & $0.6568(\mathrm{~ns})$ & 0.6914 & 0.7017 & 0.7190 & 0.7337 (NS) & 0.7174 (NS) \\
\hline average & 0.8995 & 0.9442 & 0.9568 & 0.9764 & 0.9933 & 0.9881 \\
\hline
\end{tabular}

Indicated values are those of the $\mathrm{R}^{2}$ goodness-of-fit of the curves. They are bold printed for the kind of function that provided the highest fit with the observed data. The comparisons were done on one hand, between linear, $0.33,0.50$ power and logarithmic functions and on the other hand, between linear and second-order polynomial functions, the second term of the latter bearing exponent 0.33 or 2 . (ns) and (NS): the coefficient of last term of the function is non-significant, respectively with $0.05 \leq \mathrm{P} \leq 0.10$ and $\mathrm{P}>0.10$. 

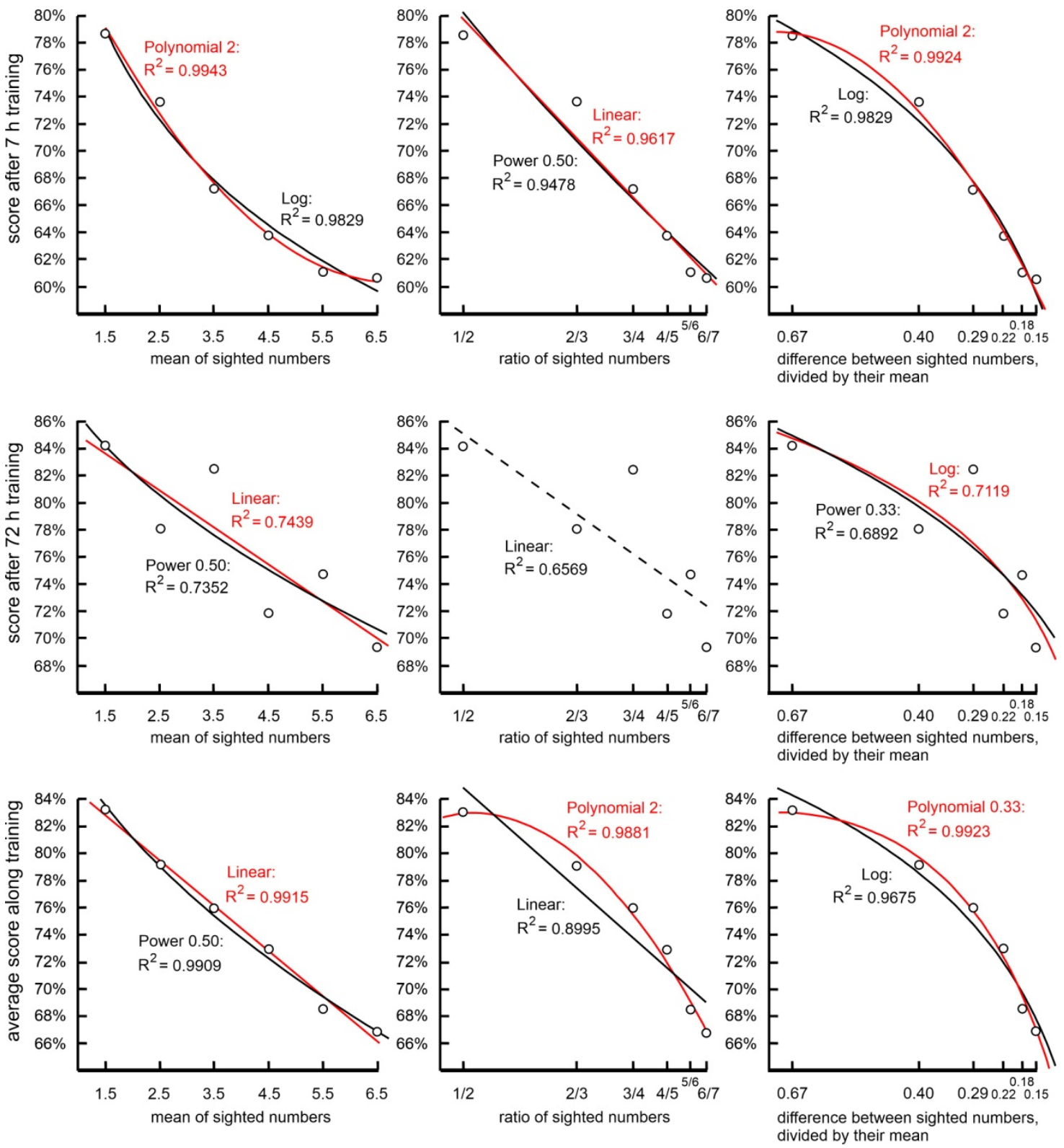

Figure 4. Relation between the ants' discrimination accuracy (y-axis) and (on the x-axis), the mean (left graphs) or the ratio (middle graphs) of sighted pairs of numbers of increasing size (i.e. non-symbolic amounts) or their difference divided by their mean (right graphs).

These relations are figured for a training time of 7 hours (upper graphs), 72 hours (middle graphs) and for the average of six assessments made in the course of 72 training hours (lower graphs). The curves drawn in red are those fitting the best to the observed data as indicated by their goodness-of-fit $\mathrm{R}^{2}$ value and by their significance level given in Table 2. The curves of second next significant highest fit are drawn in black. The dashed line is that of a relation providing the highest though non-significant fit among first-order functions.

Testing adult humans, Barrouillet and Thevenot (2013) showed a linear increase between response times and error rates in simple addition tasks using operands with a magnitude of 1 to 4 . However, as the authors noted, with such simple additions, linear and non-linear predictors can be almost collinear, and a regression analysis might not allow choosing unequivocally between a linear and a non-linear model. Dehaene (2003) already wondered that it is remarkable that linear and non-linear coding schemes could be discriminated with a range of numbers as small as 1 to 5. Indeed, the larger the range of numbers will be, the easier will be the discrimination between, for instance, power and logarithmic functions describing the accuracy of distinguishing two numbers in function of their magnitude. 
Working on children and non-symbolic amounts, Sasanguie and Reynvoet (2013) observed a size effect (assessed by their performance in a comparison task using pairs of dots differing by the same ratio), but found no relation between size effect and number line estimation (assessed by a number-to-position task). However, the authors did not use equal distance between the pairs of numbers. Different mechanisms may thus underlie the number-comparison task and the number line estimation task. In fact, there is an up growing debate concerning the relation between size effect and mental number line.

As a magnitude effect can be observed even when no comparison task between non-symbolic amounts is involved (Cantlon \& Brannon, 2006, Nieder \& Miller, 2003), Verguts, Fias, and Stevens (2005) argued that the size effect does not require access to the mental number line. Indeed, Verguts and Van Opstal (2005) showed that, experimented on humans, a same-different comparison task with small symbolic numbers showed a distance, but no size effect, distance and size effects being thus dissociated and strengthening the idea that the size effect does not originate from the mental number line. However, working with humans and by using synesthesia digit-color experiments, Cohen Kadosh, Tzelgov, and Henik (2008) showed that the size effect is task specific and contingent upon the characteristics of a mental number line representing large numbers more vaguely than smaller ones. Also, Pinhas, Tzelgov, and Guata-Yaakobi (2010) showed, by using a size congruity effect in order to analyze automatic processing of numbers, i.e. by avoiding contamination by intentionally applied strategies, that the size effect reflects a basic feature of the mental number line.

Though many works have been made on the numerosity ability of animals (see the introduction section), their mental representation of numbers on a line has rarely been examined. To the best of our knowledge, no complete work on the subject has been performed on invertebrates. Concerning the vertebrates, a few works on the topic have been conducted in birds and in primates. It has been shown that newborn chicks have a left to right oriented number line (Rugani et al., 2015). The chicks' numbers arrangement could be logarithmic or at least not strictly linear. Accidentally, while studying the pigeons' ability in subtracting, Brannon et al. (2001) found that these birds represent numbers on a mental number scale that appears to be linear instead of logarithmic (see Gallistel et al., 2001 about Dehaene's (2001) different interpretation). Three works have demonstrated the monkeys' use of a number line or at least of some native number representation: Hauser et al. (1996, 2000), Uller et al. (2001). These authors do not define if the monkeys' numbers arrangement is linear or logarithmic. In any way, it seems that these primates' responses to numbers became weaker for larger numbers.

Several studies have been performed on humans, essentially on children, and have led to the conclusion that their numbers arrangement is not linear (Banks \& Hill, 1974; Shepard, Kilpatrick, \& Cunningham, 1975), but that a logarithmic compression occurs for the largest numbers or amounts (Dehaene, 2011, pp. 265-266). However, the logarithmic numerosity scale of young children shifts to a linear scale in the course of their mathematical education (Laski \& Siegler, 2007). Some children who have difficulties in understanding mathematics appeared to be lacking the number line. They are treated thanks to particular medical program and make progress in mathematical learning in the course of their acquisition of the number line (Kucian et al., 2011). This allows presuming a native character for the number line possession.

Let us here report two neurophysiological studies, the results of which agreed with ethological observations. Nieder, Freedman, and Miller (2002) showed that the neurons of the prefrontal cortex of rhesus monkeys trained to judge whether two successive visual displays contained the same small number of items became less precisely tuned as the displayed quantity increased. Carrying on, Nieder and Miller (2003) also showed that numerical representations of visual displays in the prefrontal cortex are significantly better encoded in a non-linear than in a linear scale and that a logarithmic function fitted somewhat better to the data than a power function.

Bees have been largely studied as for their numerosity ability. Among others, they have the notion of zero, locate the zero at its due mathematical place and can be learned to add or subtract an element under some circumstances (Howard et al., 2018, $2019 \mathrm{a}, \mathrm{b}$ ). They have been showed to use absolute rather than relative numerosity when discriminating between numbers and appeared to better discriminate 2 vs 3 than 3 vs 4 (Bortot et al., 2019). The latter result resembles what we found on ants. It should thus be of interest to further investigate about the bees' discrimination between successive numbers of increasing magnitude and to look if they possess a number line.

In conclusion, based on the results of conditioning experiments, ants have a basic mental number representation: they arrange the numbers on a left to right oriented line according to the numbers magnitude, ratio or relative difference in magnitude, the relation between discrimination and relative numbers' magnitude obeying to a non-linear function, likely a logarithmic one. The ants' number positioning is thus compressed along their mental number line. As a matter of fact, these insects present basic numerosity cognitive abilities similar to those of other 
evolved animals studied as for this topic, including human children having not yet been initiated to scholar mathematics.

\section{Conflict of interests}

The authors declare that there is no conflict of interests regarding the publication of this paper.

\section{References}

Agrillo, C., Dadda, M., Serena, G., \& Bisazza, A. (2008). Do fish count? Spontaneous discrimination of quantity in female mosquitofish. Animal Cognition, 11(3), 495-503.

Agrillo, C., Miletto Petrazzini, M. E., \& Bisazza, A. (2017). Numerical abilities in fish: A methodological review. Behavioural Processes, 141(2), 161-171.

Banks, W. P., \& Hill, D. K. (1974). The apparent magnitude of number scaled by random production. Journal of Experimental Psychology, 102, 253-276.

Barrouillet, P., \& Thevenot, C. (2013). On the problem-size effect in small additions: Can we really discard any counting-based account? Cognition, 128, 35-44.

Bortot, M., Agrillo, C., Avargues-Weber, A., Bisazza, A., Miletto Petrazzini, M. E., \& Giurfa, M. (2019). Honeybees use absolute rather than relative numerosity in number discrimination. Biology Letters, 15(6), 20190138. Retrieved from https://royalsocietypublishing.org

Brannon, E. M., \& Terrace, T. S. (2000). Representation of the Numerosities 1 to 9 by Rhesus Macaques (Macaca mulatta). Journal of Experimental Psychology, 26(1), 31-49.

Brannon, E. M., Wusthoff, C. J., Gallistel, C. R., \& Gibbon, J. (2001). Numerical subtraction in the pigeon: Evidence for a linear subjective number scale. Psychological Science, 12(3), 238-243. Retrieved from https://psycnet.apa.org/record/2001-01364-009

Cammaerts, M.-C. (2008). Visual discrimination of cues differing as for their number of elements, their shape or their orientation, by the ant Myrmica sabuleti. Biologia, 63, 1169-1180.

Cammaerts, M.-C., \& Cammaerts, R. (2019a). Ants are at the first stage of the notion of zero. International Journal of Biology, 11(1), 54-65.

Cammaerts, M.-C., \& Cammaerts, R. (2019b). Ants' capability of adding numbers of identical elements. International Journal of Biology, 11(3), 25-36.

Cammaerts, M.-C., \& Cammaerts, R. (2019c). Ants fail to add numbers of same elements seen consecutively. International Journal of Biology, 11(3), 37-48

Cammaerts, M.-C., \& Cammaerts, R. (2019d). Subtraction-like effect in an ant faced with numbers of elements which includes a crossed one. International Journal of Biology, 11(4), 51-66.

Cammaerts, M.-C., \& Cammaerts, R. (2019e). Left to right oriented number scaling in an ant. International Journal of Biology, 11(4), 67-79.

Cammaerts, M.-C., \& Cammaerts, R. (2020). Ants' capability of adding and subtracting odors. International Journal of Biology, 12(1), 1-13.

Cammaerts, M.-C., Rachidi, Z., \& Cammaerts, D. (2011). Collective operant conditioning and circadian rhythms in the ant Myrmica sabuleti (Hymenoptera Formicidae). Bulletin de la Société royale belge d'Entomologie, $147,142-154$.

Cantlon, J. F., \& Brannon, E. M. (2006). Shared system for ordering small and large numbers in monkeys and humans. Psychological Science, 17(5), 401-406. Retrieved from https://www.ncbi.nlm.nih.gov

Cohen Kadosh, R., Tzelgov, J., \& Henik, A. (2008). A synesthetic walk on the mental number line: The size effect. Cognition, 106, 548-557.

Dehaene, S. (2001). Subtracting pigeons: Logarithmic or linear? Psychological Science, 12(3), 244-246.

Dehaene, S. (2003). The neural basis of the Weber-Fechner law: A logarithmic mental number line. Trends in Cognitive Sciences, 7(4), 145-147.

Dehaene, S. (2011). The number sense. New York: Oxford University Press.

Dehaene, S., Bossini, S., \& Giraux, P. (1993). The mental representation of parity and number magnitude. Journal of Experimental Psychology: General, 122(3), 371-396. 
Dehaene, S., Dehaene-Lambertz, G., \& Cohen, L. (1998). Abstract representations of numbers in the animal and human brain. Trends in Neurosciences, 21(8), 355-61.

Fischer, M. H., \& Rottmann, J. (2005). Do negative numbers have a place on the mental number line? Psychology Science, 47(1), 22-32.

Flombaum, J. I., Junge, J. A., \& Hauser, M. D. (2005). Rhesus monkeys (Macaca mulatta) spontaneously compute addition operations over large numbers. Cognition, 97, 315-325.

Gallistel, C. R., Brannon, E. M., Gibbon, J., \& Wusthoff, C. J. (2001). Response to Dehaene. Psychological Science, 12(3), 247.

Garland, A., \& Low, J. (2014). Addition and subtraction in wild New Zealand robins. Behavioural Processes, 109, 103-110.

Hauser, M. D., Carey, S., \& Hauser, L. B. (2000). Spontaneous number representation in semi-free-ranging rhesus monkeys. Proceedings of the Royal Society of London B: Biological Sciences, 26(1445), 829-833.

Hauser, M. D., MacNeilage, P., \& Ware, M. (1996). Numerical representation in primates. Proceedings of the National Academy of Sciences, USA, Psychology, 93, 1514-1517.

Howard, S. R., Avarguès-Weber, A., Garcia, J. E., Greentree, A. D., \& Dyer, A. G. (2018). Numerical ordering of zero in honey bees. Science, 360(6393), 1124-1126.

Howard, S. R., Avarguès-Weber, A., Garcia, J. E., Greentree, A. D., \& Dyer, A. G. (2019a). Symbolic representation of numerosity by honeybees (Apis mellifera): Matching characters to small quantities. Proceedings of the Royal Society, B, Biological Sciences, 286, 20190238.

Howard, S. R., Avarguès-Weber, A., Garcia, J. E., Greentree, A. D., \& Dyer, A. G. (2019b). Numerical cognition in honeybees enables addition and subtraction. Cognitive Neuroscience, 5, 1-6.

Irie, N., Hiraiwa-Hasegawa, M., \& Kutsukake, N. (2019). Unique numerical competence of Asian elephants on the relative numerosity judgment task. Journal of Ethology, 37, 111-115.

Krajcsi, A., Lengyel, G., \& Kojouharova, P. (2018). Symbolic number comparison is not processed by the analog number system: Different symbolic and non-symbolic numerical distance and size effects. Frontiers in Psychology, 9, 124.

Kucian, K., Grond, U., Rotzer, S., Henzi, B., Schonmann, C., Plangger, F., Galli, M., ..., \& von Aster, M. (2011). Mental number line training in children with developmental dyscalculia. NeuroImage, 57(3), 782-795.

Laski, E. V., \& Siegler, R. S. (2007). Is 27 a big number? Correlational and Causal Connections among numerical categorization, number line estimation, and numerical magnitude comparison. Child Development, 78(6), 1723-1743.

Merritt, D., Rugani, R., \& Brannon, E. M. (2009). Empty sets as part of the numerical continuum: conceptual precursors to the zero concept in rhesus monkeys. Journal of Experimental Psychology: General, 138(2), 258-269.

Nieder, A., \& Miller, E. K. (2003). Coding of cognitive magnitude: Compressed scaling of numerical information in the primate prefontal cortex. Neuron, 37, 149-157. Retrieved from https://www.ncbi.nlm.nih.gov

Nieder, A., Freedman, D. J., \& Miller, E. K. (2002). Representation of the quantity of visual items in the primate prefrontal cortex. Science, 297, 1708-1711. Retrieved from https://www.ncbi.nlm.nih.gov

Pearce, J. M. (2008). Animal learning and cognition: An introduction. Hove \& New York, Psychology Press.

Pepperberg, I. M. (2006). Grey parrot numerical competence: A review. Animal Cognition, 9(4), 377-391.

Pepperberg, I. M. (2012). Further evidence for addition and numerical competence by a Grey parrot (Psittacus erithacus). Animal Cognition, 15(4), 711-717.

Pinhas, M., \& Tzelgov, J. (2012). Expanding on the mental number line: Zero is perceived as the "smallest". Journal of Experimental Psychology: Learning, Memory, and Cognition, 38(5), 1187-1205.

Pinhas, M., Tzelgov, J., \& Guata-Yaakobi, I. (2010). Exploring the mental number line via the size congruity effect. Canadian Journal of Experimental Psychology, 64(3), 221-225.

Range, F., Jenikejew, J., Schröder, I., \& Virányi, Z. (2014). Difference in quantity discrimination in dogs and wolves. Frontiers in Psychology, 5, 1299. 
Reznikova, Z., \& Ryabko, B. (2011). Numerical competence in animals, with an insight from ants. Behaviour, 148(4), 405-434.

Rodriguez, R. L., Briceno, R. D., Briceno-Aguilar, E., \& Höbel, G. (2015). Nephila clavipes spiders (Araneae: Nephilidae) keep track of captures prey counts: Testing for a sense of numerosity in an orb-weaver. Animal Cognition, 18(1), 307-314.

Royston, P., \& Altman, D. G. (1994). Regression using fractional polynomials of continuous covariates: parsimonious parametric modelling. Applied Statistics, 43(3), 429-467.

Rugani, R., Vallortigara, G., Priftis, K., \& Regolin, L. (2015). Number-space mapping in the newborn chick resembles humans' mental number line. Science, 347(6221), 534-536.

Sassanguie, D., \& Reynvoet, B. (2013). Number comparison and number line estimation rely on different mechanisms. Psychologica Belgica, 53(4), 17-35. Retrieved from https://www.psychologicabelgica.com

Shepard, R. N., Kilpatrick, D. W., \& Cunningham, J. P. (1975). The internal representation of numbers. Cognitive Psychology, 7, 82-138.

Stevens, S. S. (1961). To honor Fechner and repeal his law. A power, not a log function, describes the operating characteristic of a sensory system. Science, 133, 80-86.

Uller, C., Carey, S., \& Hauser, M. (2001). Spontaneous representation of number in cotton-top tamarins (Saguinus oedipus). Journal of Comparative Psychology, 115(3), 248-257.

Uller, C., Jaeger, R., Guidry, G., \& Martin, C. (2003). Salamanders (Plethodon cinereus) go for more: Rudiments of number in an amphibian. Animal Cognition, 6, 105-112.

Umiltà, C., Priftis, K., \& Zorzi, M. (2009). The spatial representation of numbers: Evidence from neglect and pseudoneglect. Experimental Brain Research, 192, 561-569.

Vallortigara, G. (2018). Comparative cognition of number and space: The case of geometry and of the mental number line. Philosophical Transactions of the Royal Society B: Biological Sciences, 373, 20170120.

Verguts, T., \& Fias, W. (2004). Representation of number in animals and humans: A neural model. Journal of Cognitive Neuroscience, 16(9), 1493-1504.

Verguts, T., \& Van Opstal, F. (2005). Dissociation of the distance effect and size effect on one-unit digits. Psychonomic Bulletin \& Review, 12(5), 925-930.

Verguts, T., Fias, W., \& Stevens, M. (2005). A model of exact small-number representation. Psychonomic Bulletin \& Review, 12(1), 66-80.

Wittlinger, M., Wehner, R., \& Wolf, H. (2006). The ant odometer: Stepping on stilts and stumps. Science, 312(5783), 1965-1967.

Wittlinger, M., Wehner, R., \& Wolf, H. (2007). The desert ant odometer: A stride integrator that accounts for stride length and walking speed. Journal of Experimental Biology, 210, 198-207.

Zar, J. H. (1999). Biostatistical Analysis (4th ed.). Upper Saddle River: Prentice Hall.

\section{Copyrights}

Copyright for this article is retained by the author(s), with first publication rights granted to the journal.

This is an open-access article distributed under the terms and conditions of the Creative Commons Attribution license (http://creativecommons.org/licenses/by/4.0/). 